\title{
Pulling on Heartstrings: Three Studies of the Effectiveness of Emotionally Framed Communication to Encourage Workplace Pro-Environmental Behavior
}

\author{
Sally V. Russell ${ }^{1, *(D)}$ and Neal M. Ashkanasy ${ }^{2}$ (D) \\ 1 Sustainability Research Institute, School of Earth and Environment, University of Leeds, Leeds LS2 9JT, UK \\ 2 UQ Business School, The University of Queensland, Brisbane, QLD 4072, Australia; n.ashkanasy@uq.edu.au \\ * Correspondence: s.russell@leeds.ac.uk
}

Citation: Russell, S.V.; Ashkanasy, N.M. Pulling on Heartstrings: Three Studies of the Effectiveness of Emotionally Framed Communication to Encourage Workplace Pro-Environmental Behavior. Sustainability 2021, 13, 10161. https:// doi.org/10.3390/su131810161

Academic Editors: Sarah Riforgiate, Shawna Malvini Redden,

Satoris Howes, Tim Huffman,

Stacy Tye-Williams and María del Mar Molero Jurado

Received: 21 June 2021

Accepted: 6 September 2021

Published: 10 September 2021

Publisher's Note: MDPI stays neutral with regard to jurisdictional claims in published maps and institutional affiliations.

\begin{abstract}
We investigated whether the emotional framing of climate change communication can influence workplace pro-environmental behavior. In three quasi-experimental studies, we examined whether emotional displays in climate change communication affected participants' subsequent workplace pro-environmental behavior. In Studies 1 and 2, undergraduate and master's students viewed a fictional news video about climate change, where the newsreader displayed one of five emotions: sadness, fear, anger, contentment, and hope. The dependent variable was recycling behavior following the viewing. In Study 3, office employees viewed the same news videos online; the dependent variable was requesting further information to increase pro-environmental behavior in the workplace. The results from all three studies show that displayed emotion significantly affected pro-environmental behavior and that sadness, in particular, resulted in significantly less workplace pro-environmental behavior. These results indicate the need to study the effect of discrete emotions, rather than assuming that emotions of the same valence have similar effects. The results also underscore the importance of using experimental designs in advancing the field. We conclude with a discussion of the implications of our findings for research, theory, and practice of emotionally framed communication of sustainability messages.
\end{abstract}

Keywords: discrete emotion; emotional arousal; recycling; climate change; workplace pro-environmental behavior; quasi-experimental

\section{Introduction}

Climate change is one of the world's most pressing issues. There is no longer any doubt that significant and sustained action is necessary in order to minimize the effects of global warming and to avoid the irreversible and potentially catastrophic consequences of climate change [1]. Increasing evidence shows that wicked problems like climate change often evoke strong emotional reactions including fear, anxiety, and, in some cases, depression about the future [2-4]. Some researchers have begun to investigate emotions as they relate to climate change communication [5,6], climate change perceptions [7], and motivation to act $[8,9]$. Within climate change communication, the use of negative emotions is common, with fear and anxiety featuring prominently [5-7,10,11]; positive emotions, such as hope, are used less commonly $[5,6,12]$. This work clearly shows that emotions are strongly related to pro-environmental behavior, yet an understanding of the causal relationships is lacking [6,7].

In our research, we aimed to advance the current understanding of the causal relationships between climate change communication, emotion, and behavior using a quasiexperimental design. To date (and as we noted earlier), research has been dominated by correlational studies. Moreover, there has been very limited experimental research used to understand the relationship between emotion, communication, and climate change [7]. Therefore, we opted to use an experimental methodology to advance further understanding 
of the relationships between discrete emotions in climate change communications and the subsequent enactment of pro-environmental behavior.

We make a second contribution to the research by examining behavior in the specific context of the workplace. Businesses and organizations have contributed much to the production of escalating greenhouse gas emissions but they also offer opportunities to reverse this trend by developing innovative solutions that decarbonize our economies [13,14]. Yet, the success of any business initiative relies on the collective efforts and the accumulation of pro-environmental behaviors of their employees [14-16].

We define employees broadly to mean those employed by the organization at any level. Thus, we did not focus specifically on one group of employees (e.g., the CEO, senior management team, or sustainability managers); rather, we considered employees more broadly, and we are interested in behavior across all levels of the organization. We also took a broad perspective in defining workplace pro-environmental behavior as actions taken by employees that improve the environmental performance of their company [17]. Thus, our definition parallels definitions of employee green behaviors [18-20], employee proenvironmental behavior (e-PEB) [21], as well as employee-level (or micro-level) corporate social responsibility behaviors [22,23]. While we recognize that there are many definitions of workplace pro-environmental behavior, our aim was not to debate which definition is more accurate nor to delve into the nuances of differentiating between definitions but to encapsulate the core meaning of employee behavior that advances sustainability within the organization.

Most research that explores employee-level sustainability behavior (such as the theory of planned behavior [24] and value-belief-norm theory [25]) utilize psychological models. These theories suggest that cognitive variables (including attitudes, beliefs, and norms) are important in explaining an individual's intention to engage in a specific behavior, which then affects their subsequent behavior. While there is no doubt that this research has advanced our understanding substantively $[23,26,27]$, more remains to be investigated. In particular, the role of emotion in understanding workplace pro-environmental behavior is lacking [28,29] — despite growing evidence that climate change is an emotional topic for employees $[4,30]$ and that emotions are an important driver of workplace pro-environmental behavior $[9,29]$.

We define emotion in terms of the "circumplex model", in which emotion is modeled in two dimensions: (1) valence and (2) arousal [31]. Valence refers to the hedonic quality (pleasure or displeasure) associated with emotion. Arousal (also called activation or intensity) refers to felt activation or the strength of the emotional experience [31,32]. All affective stimuli (e.g., emotions such as anger, sadness, hope, and joy, as well as nonemotional affective states such as fatigue or tiredness) can be defined as combinations of valence and arousal.

From this perspective, emotions can be described as a transient state that arises on the spot in response to a stimulus, and therefore, they are different from other affective states like moods. This is because emotions are aroused in response to a specific stimulus [33]. Emotions also serve as information-processing mechanisms that help individuals to distinguish the relevance and importance of events or information [34], otherwise known as emotional appraisals [35]. Thus, a focus on emotions is crucial to understanding organizational decision-making and behavior [36], particularly in relation to sustainability [4,6,30,37]. We argue, therefore, that our research is important in progressing the understanding of the relationship between emotional reactions and workplace pro-environmental behavior.

\section{Theoretical Framework and Hypothesis Development}

The underlying theoretical model for the present research is affective events theory (AET) $[38,39]$. This theory parallels Brosch's [7] perspective on the determinants of climate change action and has also previously been applied to a workplace pro-environmental behavior perspective [40]. Using AET as a basis suggests that behaviors can be grouped into two categories: "affect-driven" and "judgment-driven." Affect-driven behaviors follow 
directly from affective experience and are not mediated by cognition. In contrast, judgmentdriven behaviors are mediated by a cognitive evaluation. The resulting behaviors are the outcome of measured decisions that consider an overall evaluation of the situation or event. Our aim in this research was to examine affect-driven behavior and thence to examine the causal effect of discrete emotions on pro-environmental behavior.

According to AET, people often respond emotionally to events or issues. An event can be described as "a happening, especially an important happening" [38] (p. 31). In this way, climate change could be considered an "event" in the context of AET. The emotions that arise as a result of events or issues have a direct influence on behaviors. Despite this, and as many researchers note $[7,28,29,40]$, the impact of emotional reactions to climate change on subsequent behavior has yet to be explored fully.

Researchers who have studied the nexus of climate change and emotions report finding that climate change is an emotive issue, generally $[6,11,41]$, as well as within a workplace context $[9,28-30,40]$. Yet, as also noted by leading researchers in the field, research has tended to focus mainly on the valence of emotion-with limited research exploring the effects of discrete emotions on pro-environmental behavior $[6,7,12]$. The focus on emotional valence has been useful to establish the importance of emotion as a driver or motivation for pro-environmental behavior; however, it has also resulted in a lack of attention paid to the inherent complexity of the effects of discrete emotions [6].

In addition, many scholars $[6,12,29,42]$ have made the point that it is no longer sufficient to study emotion in terms of simply positive and negative affective valence. This is because discrete emotions with a particular affective valance (e.g., anger and sadness are both examples of negative affect) can have differential effects. Chapman, Lickel, and Markowitz [6], for instance, call for a "more nuanced, evidence-based understanding of the multiple and sometimes counterintuitive ways that emotion, communication and issue engagement are intertwined" (p. 850). In the present research, therefore, we make a contribution to the literature on sustainability by examining how discrete emotions might determine pro-environmental behavior.

In the present research, we elected to study five discrete emotions within each of the four quadrants of the circumplex model: (1) sadness-a low arousal negative emotion, (2) anger and fear-high arousal negative emotions, (3) contentment-a low arousal positive emotion, and (4) hope-a high arousal positive emotion. We used emotional expressions from a series of qualitative interviews and contemporary reviews of current relevant literature $[4,7,30,37]$ to guide the selection of these five discrete emotions.

In Section 2.1, we present our specific hypotheses for each of the five emotions, drawing on AET [38,39] and Lazarus's [35] theory of action tendencies. We integrated these perspectives with the current research on sustainability, environmental psychology, and management studies. At the same time, we recognize that no individual emotion can play a prototypical role in stimulating behavior [6,35]. Our aim, instead, was to conduct a comparison between five discrete emotions, with the goal of further exploring the relationship between emotional reactions to climate change and workplace pro-environmental behavior.

\subsection{Negative Emotions}

Negative emotions are evoked primarily by unfavorable or unpleasant events or interactions [35]. Researchers [7,12] have found that aggregated negative emotions can have a positive effect on pro-environmental behavior. Nonetheless, while all negative emotions share a common unpleasant primary appraisal, discrete emotions, such as anger, fear, and sadness, are associated with different behavioral tendencies [35,43], and the nature of discrete emotion effects has not been fully explored (many argue that it, thus, warrants further attention $[6,7,42,44])$. We explored the specific negative emotions of sadness, fear, and anger.

The emotion of sadness is generally viewed as an unpleasant emotion, with neither high nor low arousal $[31,45]$. We use the term sadness to refer to low arousal negative emotions, rather than an unpleasant state per se. Lazarus suggests that sadness is generally 
associated with "irrevocable loss" or a "sense of helplessness about restoration of the loss", as well as the absence of blame [35] (p. 248). Thus, our definition of sadness differs from others that describe it as a general negative emotion rather than being at the lowest level of arousal [46].

Higgins [47] argues that sadness can be classified as a dejection-related emotion and suggests it is related to a low motivational state. According to Lazarus [35], sadness is associated with inaction (or withdrawal). It differs, therefore, from other negative emotions in that the sadness action is passive through withdrawal, rather than the more active tendency associated with higher arousal emotions, such as fear or anger [35]. Given that sadness is related to a lack of motivation [47] and a tendency towards inaction [35], we predicted the following:

Hypothesis 1 (H1). Sadness leads to less workplace pro-environmental behavior than no emotion.

We note that this prediction contradicts a recent finding that viewing sad climate communications may induce more pro-environmental behavior [46]. Nonetheless, we argue that the application of our theoretical framework [35,39] clearly suggests a negative relationship between sadness and pro-environmental behavior.

Within the circumplex model of emotion, fear is a high arousal negative emotion [45]. Appraisal theorists further suggest that fear is generally associated with an uncertain existential threat and a lack of control over future events [43], as well as a tendency to take action by retreating or escaping [35]. Research has shown that fearful individuals have heightened attention to information [48] and messages [11], make more pessimistic judgments and choices [49], and demonstrate increased climate change policy support [41]. Despite evidence from the health communication literature that fear-based messaging can lead to a passive state of avoidance, within the context of climate change research [7], we would argue that there is more evidence that fear leads to active behaviors. Based on this literature, we hypothesized the following:

Hypothesis 2 (H2). Fear leads to more workplace pro-environmental behavior than no emotion.

Previously, we argued that discrete emotions that share the same valence may have differential effects $[6,38,42]$. Since we hypothesized that sadness is associated with a tendency for inaction and fear has a tendency for action, we further hypothesized the following:

Hypothesis 3 (H3). Fear leads to more workplace pro-environmental behavior than sadness.

Similar to fear, anger is classified as a high arousal negative emotion [45] and can be described as a "demeaning offence against me and mine" [35] (p. 222). Anger is also associated with a sense that the self (or someone we care about) has been offended or injured, a sense of certainty about what has happened and its cause, and a belief that another person or entity caused the negative event $[35,50]$.

In exploring action tendencies, anger has been found to link to a desire to change the situation and to move against an obstacle by fighting it [51]. Lerner and her colleagues [49] further found that a central part of being angry is the belief that individuals will get what they want, and have likened the behavioral tendency of anger to hope, optimism, and happiness $[43,52]$. This literature supports the following prediction:

Hypothesis 4 (H4). Anger leads to more workplace pro-environmental behavior than no emotion.

Consistent with this line of argument, we further expected that anger (a high arousal emotion with a clear action tendency) would have a greater effect on intention and behavior than sadness (low arousal with a tendency for inaction). Therefore, we predicted the following: 
Hypothesis 5 (H5). Anger leads to more workplace pro-environmental behavior than sadness.

Although anger and fear are similarly positioned within the emotion circumplex, Lerner and Keltner [49] found that angry and fearful individuals make distinctly different decisions; angry individuals make relatively optimistic choices, whereas fearful individuals make pessimistic choices. Lazarus [35] also differentiates between fear and anger. He suggests that while fear tends to be associated with the action tendency to escape, retreat, or avoid, anger tends to be associated with the tendency to fight. Taken together, the work of Lazarus [35] and Lerner and colleagues [49,52] suggests that anger may result in a more proactive response to environmental issues than fear. Therefore, we lastly predicted the following for negative emotions:

Hypothesis 6 (H6). Anger leads to more pro-environmental behavior than fear.

\subsection{Positive Emotions}

Positive emotions have traditionally received relatively less attention than negative emotions. This has been particularly true for studies on climate change, in which hope has traditionally been the dominant focus of positive emotion studies [12,41,44]. Although studies are dominated by a focus on high arousal emotions, such as hope, there is also evidence that low arousal positive emotions may have a significant effect in promoting helpful and sociable behavior $[53,54]$. We drew on this literature (together with research from environmental psychology and management) to derive specific hypotheses in relation to the two positive emotions of contentment (low arousal positive) and hope (high arousal positive).

Within the circumplex model, contentment can be described as a low arousal positive emotion [31,55]. In this regard, Lazarus [35] classifies contentment as synonymous with joy and happiness, but with a less intense reaction. Based on this interpretation, low arousal positive emotions can be expected to result in approach behaviors, including reaching out to others, but with less strength than the behavioral tendency associated with high arousal positive emotions, such as hope. Seo and his colleagues [32] further noted that less attention has been paid to low arousal emotions, such as contentment, and that it is, therefore, important to examine low arousal emotions to expand the understanding of emotions beyond the dominance of high arousal emotions.

Research has shown that people in whom mild positive affect has been induced are more helpful and generous to others and are more socially responsible [53]. While this finding suggests that mild positive emotion may induce pro-social behavior, much less is known about whether these behavioral implications can be extended to an environmental context [44].

Drawing on the action tendencies described by Lazarus [35], and with the aim of testing whether previous results extend to the natural environment, we thus predicted the following:

Hypothesis 7 (H7). Contentment will lead to greater pro-environmental behavior than no emotion.

Within the circumplex model, hope is generally mapped as a high arousal positive emotion [32], according to Lazarus [35]. As such, the core relational theme of hope is not gaining a desired outcome but longing for the amelioration of a dreaded outcome. To put it simply, hope is to fear the worst but long for better [35]. Thus, hope is pertinent in considering emotional reactions to climate change. Hope can be classified as a high arousal emotion because, like the other high arousal emotions of joy, anger, and fear, it is associated with an increase in the intensity of an individual's mental state [56]. In his earlier work, Lazarus [35] suggested that hope can result in moving toward rather than away from a desired outcome. This is because hopeful people remain committed and do not give up on the desired outcome. Lazarus [56] later suggested that hope can act as a 
call to action, yet the extent to which hope is associated with a strong action orientation remains an empirical question.

Within the climate change literature, there is also evidence that hope is positively related to support for climate change mitigation policies [41], climate-related political participation [57] and support [58], as well as self-reported pro-environmental behavior [3]. Despite this, critics of hope-based appeals [12] have shown that emphasizing progress on climate change action may lead to complacency. Thus, while hope can lead to pro-environmental behavior, there is a need to focus on emphasizing solution-oriented individual and collective action rather than focusing on how general progress in climate change mitigation $[7,44]$. With this caveat, we hypothesized the following:

Hypothesis 8 (H8). Hope leads to more pro-environmental behavior than no emotion.

Evidence suggests that emotional arousal may be more important for negative emotions than for positive emotions, particularly in the context of environmental issues. In this regard, research has shown that individuals often pay more attention to negative stimuli compared to positive stimuli of the same intensity. Lewicka and her colleagues [59] labeled this phenomenon the "negativity effect", and suggested that when present, arousal results in a greater effect of negative than positive stimuli on behavior, affect, and judgments. Similarly, research by Isen and her colleagues tells us that mild positive affect can have a significant effect on behavior $[53,60]$, thereby implying that for positive emotion, high arousal is not necessary in order to induce behavior change. Both Lewicka et al. [59] and Isen [53] suggested that this effect is particularly relevant to moral issues and sociable and helpful behavior.

Many researchers have examined the effect of positive and negative emotions independently. However, this type of approach can mask potential differences or similarities in response to positive and negative emotions. Moreover, and as Weiss and Cropanzano [38] argue, being aroused into a positive state has an effect that may not necessarily be the opposite of the effect of being aroused into a negative state. This suggestion is consistent with our hypotheses that pro-environmental behavior can result from the inducement of the high arousal negative emotions of anger and fear, as well as from the positive emotions of hope and contentment.

It is important to note, however, that the effects of positive and negative emotions are not symmetrical [39] and that more research is needed to compare the effects of positive and negative emotions. Evidence also suggests that individuals are primed to pay more attention to negative news reports than positive ones [61] and that the effect of negative emotions is more likely in cases in which the emotional content refers to a moral or prosocial issue [59].

Considering the totality of this research, we argue that the effect of emotional arousal on pro-environmental behavior will be more pronounced for negative emotions than for positive emotions. To test this assertion, we proposed two additional hypotheses, as follows:

Hypothesis 9a (H9a). The difference in induced pro-environmental behavior between fear and sadness is greater than that between hope and contentment.

Hypothesis $9 \mathbf{b}(\mathbf{H 9 b})$. The difference in induced pro-environmental behavior between anger and sadness is greater than that between hope and contentment.

\section{Materials and Methods}

We tested our hypotheses in three quasi-experimental studies. In Studies 1 and 2, which we conducted in laboratory settings, we used convenience samples of undergraduate and master's students. Noting the limitations of these samples, we subsequently conducted a third study (Study 3) in a field setting, using fully randomized allocation. We employed a post-test-only design in all three studies. Manipulated independent variables were the 
five emotions of (1) sadness, (2) fear, (3) anger, (4) contentment, and (5) hope. We also incorporated a "no emotion" neutral control group. In all three studies, felt emotion was the independent variable and the dependent variable was pro-environmental behavior. All participants gave their informed consent to take part in the research before they participated in the study and the study was conducted in accordance with the Declaration of Helsinki and the Australian National Statement on Ethical Conduct in Human Research (2007). The research protocol was approved by the Human Research Ethics Committee of Griffith University (MGT/21/09/HREC).

\subsection{Experimental Manipulations}

Using the same experimental manipulations across all three studies, we assigned participants to one of seven conditions comprising five treatment conditions and two control conditions. The experimental manipulations consisted of videos designed to manipulate the discrete emotions of sadness, fear, anger, contentment, and hope. In the five experimental conditions, we showed participants bespoke fictional news reports about the impact of climate change on business. We made the news reports as similar as possible, incorporating small changes to manipulate the emotions expressed within each report.

We trained actors to display emotion in their facial expressions, body language, and voices. Training materials made use of the Facial Action Coding System [62]. The database includes images of facial expressions and descriptions of the facial expressions, body language, and voices appropriate for each specific emotion.

The news reports also contained footage relevant to the climate change story. We selected this footage based on the International Affective Picture System [63], which is a database of still images that have been shown to generate consistent emotional reactions. The three negative conditions (sadness, fear, and anger) included footage of black smoke being released from factory smokestacks and a bulldozer collecting garbage at a land-fill site. Similar still images have been shown consistently to generate negative emotions [63]. In the two positive conditions, the footage included video footage of a wind turbine and a time-lapse video of solar panels following the sun, with a background of blue sky and white clouds. Previous research [63] found that still images of blue sky consistently evoke positive emotions.

We also made additional changes to the wording in each manipulation; specifically, we used key emotion words in each of the scripts to enhance the emotional message of the manipulation. For example, the sadness condition included "disheartening" and "hopelessness"; the fear condition included "frightening", "alarmed", and "concerned"; the anger condition included key emotion words of "anger", "annoyed", and "frustrated"; the contentment condition included "confident" and "confidence"; the hope condition included "exciting", "hope", and "encouraging".

In the audio-visual control condition, we showed participants a similar video, but with all emotional language removed. The control condition also excluded any climate-changerelated footage. In the second control condition, participants read a written transcript of the news report rather than viewing a video. The written transcript included the same information contained in the video manipulations, but we removed all emotional language. Manipulation checks showed that the manipulations were successful in inducing the specified emotion for participants (see Appendix A for full results of the manipulation checks).

\subsection{Study 1}

We recruited Study 1 participants from master's and undergraduate degree business courses at two universities located in the northeast of Australia. The final sample included 303 respondents, 57\% of whom were female, with an average age of 26 (ranging from 19 to 57). Participants were offered a small incentive of candy in return for participation.

We conducted Study 1 in a classroom setting, where we randomly assigned the participants to one of seven conditions (five audio-visual treatment conditions, one written neutral control condition, and one audio-visual control condition). Upon entering the 
laboratory, we gave participants an information sheet and asked them to create a unique alphanumeric identifier to allow us to collate their responses over the course of the study. We then showed participants the audio-visual or written news report transcript and asked them to complete a survey booklet that formed a filler task. When the survey was complete, we asked the participants to turn in their survey booklet and to dispose of their unique identifier sheet upon leaving the room. Participants had the opportunity to dispose of their sheet in a regular garbage can or a box clearly marked "Paper recycling". Prior to the experiment, one completed unique identifier sheet was placed in each bin to avoid potential modeling bias of participants following the decision of the previous participant.

\section{Measures}

We used a behavioral observation measure to gauge participants' pro-environmental behavior. Upon leaving the laboratory, participants were asked to dispose of the piece of paper they used to create their unique identifier. We coded pro-environmental behavior as 1 if a participant disposed of the sheet in the recycling box, and as 0 if they put it in the regular garbage can.

Demographic control variables included age, gender, and ethnicity. We also assessed social desirability using a ten-item version of the Marlowe-Crowne Social Desirability Scale (MC-II) [64]. We found no significant relationship between social desirability and any of the variables in the study and, therefore, we did not include it in our analyses.

\subsection{Study 2}

As in Study 1, we recruited participants for Study 2 from masters and senior undergraduate business courses at an Australian university. The final sample included 194 respondents, $47 \%$ of whom were female, with an average age of 26 , ranging from 19 to 50 years. We offered participants a small incentive of a coffee voucher or candy in return for participation.

Study 2 was conducted in a classroom setting using the same procedures and measures as for Study 1. We serially assigned twelve class groups to one of six conditions (five audiovisual treatment conditions and a written neutral control condition). The results of the manipulation check and Study 1 demonstrated the equivalence of the audio-visual and written control conditions and, therefore, we selected only a written control in this study. Furthermore, Koehler, Yadav, Phillips, and Cavazos-Kottke [65] showed that audio and visual communications enhance information about mood and tone that are not easily interpretable from textual documents. Therefore, we considered a written transcript to be an effective control condition. As in Study 1 (and as suggested by Cook and Campbell [66]), we measured demographic control variables to test for group equivalence and to overcome non-random assignment.

\subsection{Study 3}

In Study 3, we sought to overcome some of the limitations of conducting laboratory studies by replicating Studies 1 and 2 with a randomized sample of working adults. The stimulus material we used was identical to Studies 1 and 2, but this time, respondents were adults working in an office environment and they viewed the news clips and responded online.

We recruited the participants for Study 3 from three Australian sources, including a not-for-profit organization $(\mathrm{N}=114)$, a tertiary education institution $(\mathrm{N}=27)$, and invitations passed on by study participants (snowballing; $\mathrm{N}=23$ ). We found no differences in the study variables between the three samples, so they were aggregated for the analysis. We did, however, remove 29 cases because of incomplete responses or failure to continue past the manipulation. Therefore, the final sample comprised 135 respondents, $80 \%$ female, with an average age of 43 , ranging from 18 to 64 years.

The design of Study 3 followed a similar methodology to Studies 1 and 2 but was conducted online. We sent potential participants an invitation email with a link to an 
online survey. When participants clicked on the link, they were randomly directed to one of the survey conditions, which included a streaming news video (treatment conditions) or a written news transcript (control condition). Once participants had watched the video or read the transcript, they were instructed to complete the rest of the survey that included measures of the manipulation checks, demographic information, and the dependent variable. Debriefing information was presented on the final page of the survey.

\section{Measures}

To measure pro-environmental behavior in Study 3, we used information-seeking behavior. This comprised a question at the end of the online session where we asked participants if they would like to be sent additional information on pro-environmental behavior in the workplace. We coded responses as 1 if participants requested information or 0 if they did not.

We measured demographic variables to control for age, gender, and ethnicity. The analyses showed no significant differences between the groups for any of the demographic variables, so the controls were not included in further analyses. Finally, we assessed social desirability using a ten-item version of the MC-II [64]. As we found no significant relationship between social desirability and any of the variables in the study, we did not include this variable in any further analyses.

\section{Results}

\subsection{Study 1}

\subsubsection{Test of Group Equivalence}

Following a check of the analysis assumptions, we conducted a one-way betweengroups ANOVA to test for demographic differences between groups. There were significant differences between the groups for age, $F(6,297)=7.20, p<0.01$, and ethnicity, $F(6,301)=3.62, p<0.01$. There were no significant sex differences between the condition groups, $F(6,302)=2.01$, ns. As recommended by Tabachnick and Fidell [67], we used a blocking technique to group participants based on age and ethnicity. This technique revealed no significant differences for the dependent variable for different ages or ethnic groups.

\subsubsection{Hypothesis Tests}

Based on the results of logistic regression analyses, the manipulations had a significant effect on participants' recycling behavior, $\chi^{2}(6, n=303)=28.23, p<0.01$. The proportions of participants in each condition group who engaged in pro-environmental behavior (recycling) are shown in Figure 1.

The results show that participants in the sadness condition group recycled significantly less than those in the written control condition group, $\chi^{2}(1, n=99)=7.30, p<0.01$, as well as significantly less than those in the neutral audio-visual control condition group, $\chi^{2}(1, n=87)=15.31, p<0.01$. Thus, these results provide support for Hypothesis 1 .

We found no support for Hypothesis 2 insofar as fear did not result in more recycling behavior than in the written control condition group, $\chi^{2}(1, n=96)=0.00$, ns, or the audiovisual control condition group, $\chi^{2}(1, n=84)=1.42, n s$. The results show that significantly more participants recycled in the fear condition group than those in the sadness condition group, $\chi^{2}(1, n=75)=5.34, p<0.05$, thus providing support for Hypothesis 3 .

We also found no support for Hypothesis 4; anger did not result in more recycling behavior than in the written control condition group, $\chi^{2}(1, n=96)=0.00$, ns, or the audio-visual control condition group, $\chi^{2}(1, n=84)=2.20$, ns. We did, however, find that significantly more participants in the anger condition group recycled than those in the sadness condition group, $\chi^{2}(1, n=75)=4.23, p<0.01$, thus providing support for Hypothesis 5. We found no significant difference between recycling behavior in the anger condition group and the fear condition group, $\chi^{2}(1, n=72)=0.00, n s$, thus providing no support for Hypothesis 6. 


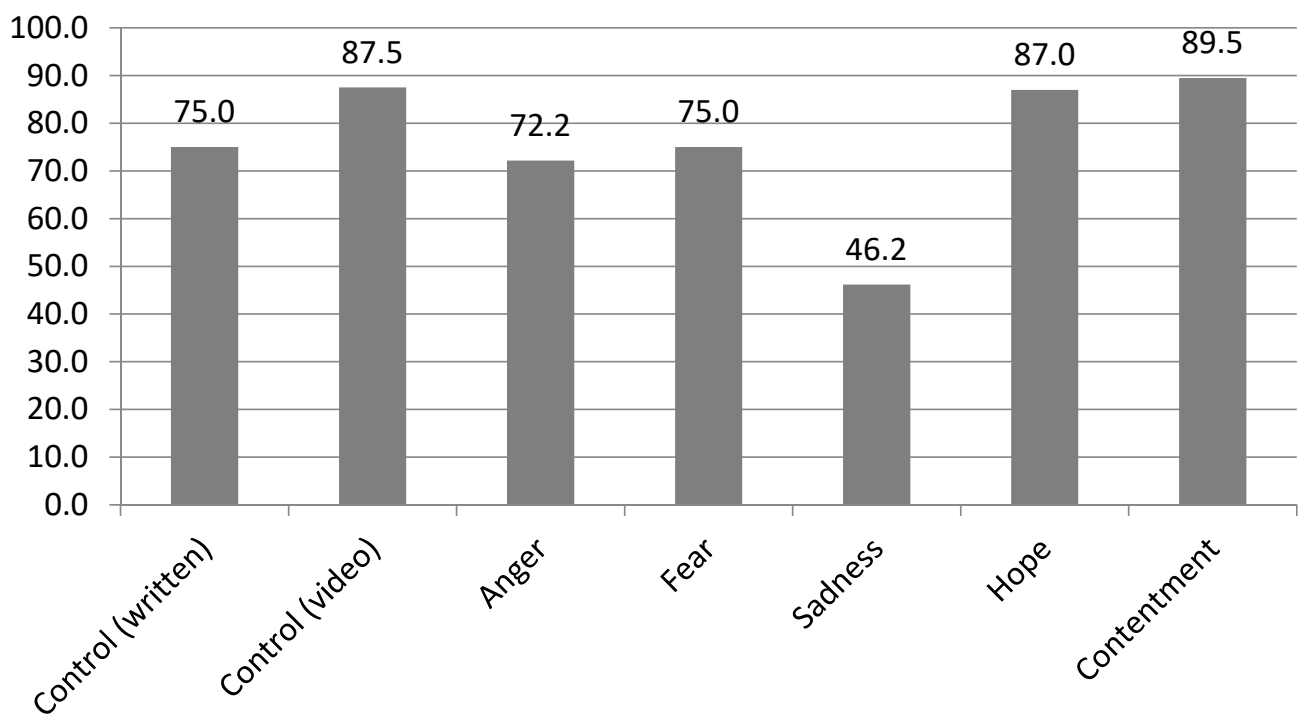

Figure 1. Percentage of Study 1 participants who recycled, $N=303$.

We also found no support for Hypothesis 7; contentment did not result in more recycling behavior than in the written control condition group, $\chi^{2}(1, n=98)=2.26$, $n s$, or the audio-visual control condition group, $\chi^{2}(1, n=86)=0.00, n s$. We also found no support for Hypothesis 8; there was no significant difference in recycling behavior between those in the hope condition group and those in the written control condition or the audio-visual control condition groups $\chi^{2}(1, n=106)=1.65, n s$, and $\chi^{2}(1, n=94)=0.00, n s$, respectively.

For our comparative hypotheses, we found support for both hypotheses. Regarding Hypothesis 9a, while the difference between the anger and sadness condition groups was significant, we found no significant difference between the contentment condition and the hope condition groups, $\chi^{2}(1, n=84)=0.00$, ns. Regarding Hypothesis $9 \mathrm{~b}$, we found a significant difference in recycling behavior between the fear and sadness condition groups, but not between the contentment and the hope condition groups.

Overall, the results of Study 1 demonstrate that the emotion displayed in news reports significantly affected the participants' subsequent pro-environmental behavior. The results of Study 1 highlight the importance of studying discrete emotions [6,7]. They show that the effect of sadness was a reduction in recycling behavior (compared to the anger and fear conditions).

We also found, as we anticipated, that the effect of emotional arousal on pro-environmental behavior was more pronounced for negative emotions than for positive emotions. The results show that participants in the fear and anger condition group (high arousal negative) recycled more often than those in the sadness condition group (low arousal negative). Examining positive emotions, however, we found no significant differences between the participants' recycling behavior in the hope (high arousal positive) condition group as compared to the contentment (low arousal positive) condition group.

\subsection{Study 2}

\subsubsection{Test of Group Equivalence}

Following a check of the analysis assumptions, we conducted a one-way betweengroups ANOVA to test for demographic differences between groups. The results show significant differences between the groups for ethnicity, $F(5,182)=11.35, p<0.01$, but no significant differences between the groups for age, $F(5,182)=2.24$, $n s$, or sex, $F(5,182)=0.66$. Further analyses revealed no significant differences in the dependent variable for the different ethnic groups. 


\subsubsection{Hypothesis Tests}

Based on the results of logistic regression analyses, the manipulation of emotional display in the video had a significant effect on the participants' recycling behavior, $\chi^{2}(5, n=179)=70.00, p<0.01$. We tested specific hypotheses relating to recycling behavior using Chi-square tests for independence (with the Yates continuity correction). The proportions of participants in each condition group who engaged in pro-environmental behavior (recycling) are shown in Figure 2.

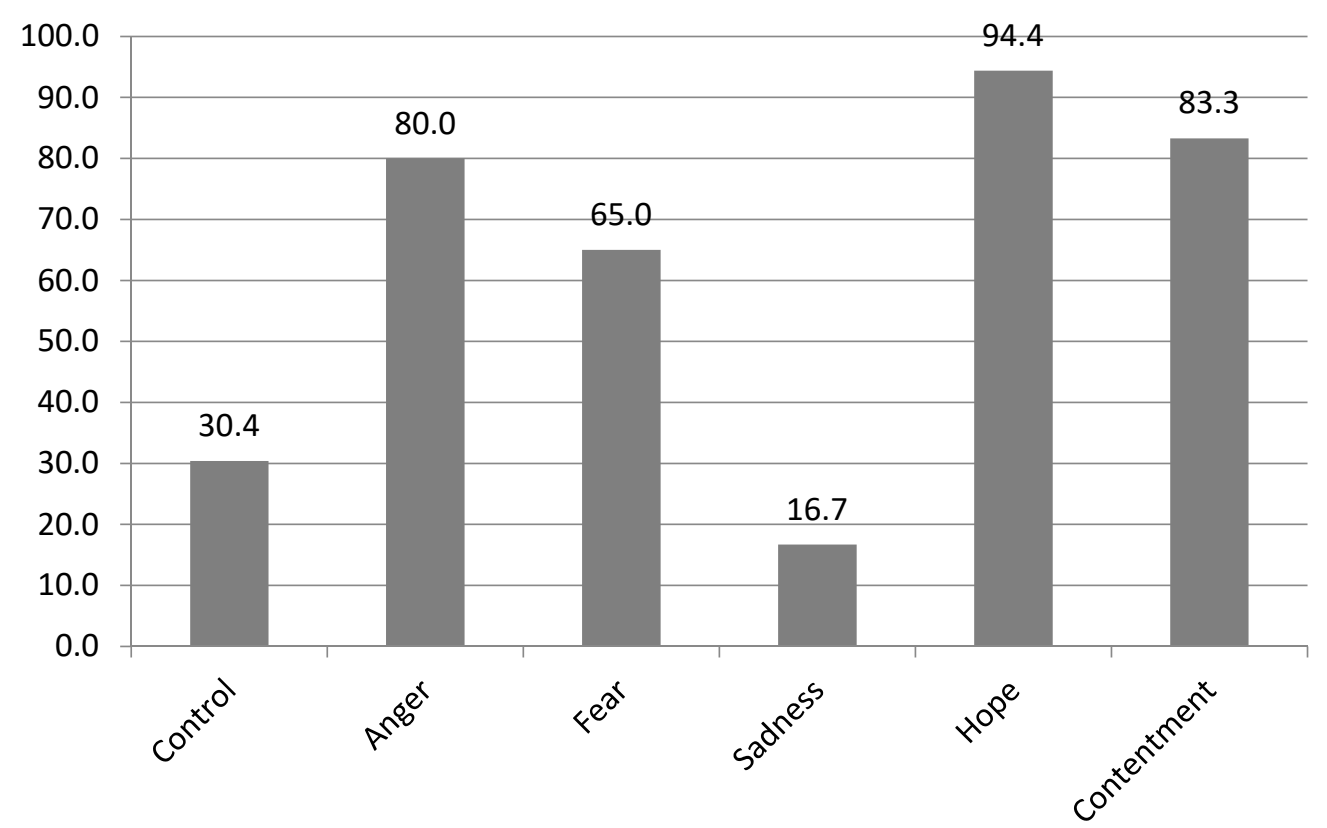

Figure 2. Percentage of Study 1 participants who recycled, $N=194$.

While a smaller proportion of participants in the sadness condition group recycled compared to those in the control condition group, this difference failed to reach significance, $\chi^{2}(1, n=83)=1.18, n s$, thus providing no support for Hypothesis 1 . We did find support for Hypothesis 2 , as significantly more participants recycled in the fear condition group as compared to the control condition group, $\chi^{2}(1, n=63)=5.68, p<0.05$. We also found support for Hypothesis 3 since fewer participants recycled in the sadness condition group as compared to the fear condition group, $\chi^{2}(1, n=100)=22.28, p<0.01$.

The results further show that a larger proportion of participants engaged in recycling behavior in the anger condition group than did those in the control condition group, $\chi^{2}(1, n=43)=8.67, p<0.01$, thus providing support for Hypothesis 4 . We also found support for Hypothesis 5 insofar as fewer participants in the sadness condition group recycled compared to those in the anger condition group, $\chi^{2}(1, n=80)=24.62, p<0.01$. Although the proportion of participants who recycled in the anger condition group was higher than for the fear condition group, this difference was not significant, $\chi^{2}(1, n=60)=0.80, n s$; therefore, we found no support for Hypothesis 6.

A significantly greater proportion of participants in the contentment condition group engaged in recycling behavior than did those in the control condition group, $\chi^{2}(1, n=41)=9.34, p<0.01$, thus providing support for Hypothesis 7. Hypothesis 8 is also supported; compared to the control condition group, significantly more participants in the hope condition group recycled, $\chi^{2}(1, n=41)=14.51, p<0.01$.

The results again support the comparative Hypotheses $9 \mathrm{a}$ and $9 \mathrm{~b}$ insofar as we found significant differences between the anger and sadness condition groups, and between the fear and sadness condition groups, but no significant difference in the recycling behaviors of those in the contentment condition group as compared to that of the hope condition group, $\chi^{2}(1, n=36)=0.28$, ns. 
Overall, the results of Study 2 are consistent with Study 1 in demonstrating that emotional arousal has a significant effect on participants' subsequent pro-environmental behavior. We found recycling in the anger, fear, hope, and contentment condition groups to be significantly more frequent than in the control condition group. These results further underscore the importance of emotion in understanding behavior in general $[36,68]$ and pro-environmental behavior specifically [6,7].

The results of Study 2 further demonstrate the importance of studying discrete emotions $[6,7,32]$. Moreover, the results show that anger and fear positively affected recycling behavior, and sadness reduced recycling (compared to the high arousal emotion conditions). These findings lend empirical support to the argument that aggregating emotion solely in terms of valence can mask nuances in the effects of discrete emotion on behavior [6,7]. We also found that the effect of emotional arousal on pro-environmental behavior is more pronounced for negative than for positive emotions, which is consistent with the results from Study 1.

\subsection{Study 3}

\subsubsection{Test of Group Equivalence}

Following a check of the analysis assumptions, we conducted a one-way betweengroups ANOVA to test for demographic differences between the groups. We found no significant differences between the groups for age, $F(5,93)=0.31$, $n s$, sex, $F(5,95)=0.20$, $n s$, or ethnicity, $F(5,169)=0.72, n s$.

\subsubsection{Hypothesis Tests}

As we did in Studies 1 and 2, we employed logistic regression analysis to see if the experimental conditions had a significant effect on information requesting behavior (a dichotomous variable). The results show that the experimental conditions significantly affected information requests, $\chi^{2}(5, n=110)=11.29, p<0.05$. We further tested specific hypotheses relating to information requests using Chi-square tests for independence (with the Yates continuity correction). The proportions of participants in each condition group who engaged in pro-environmental behavior (information requesting) are shown in Figure 3.

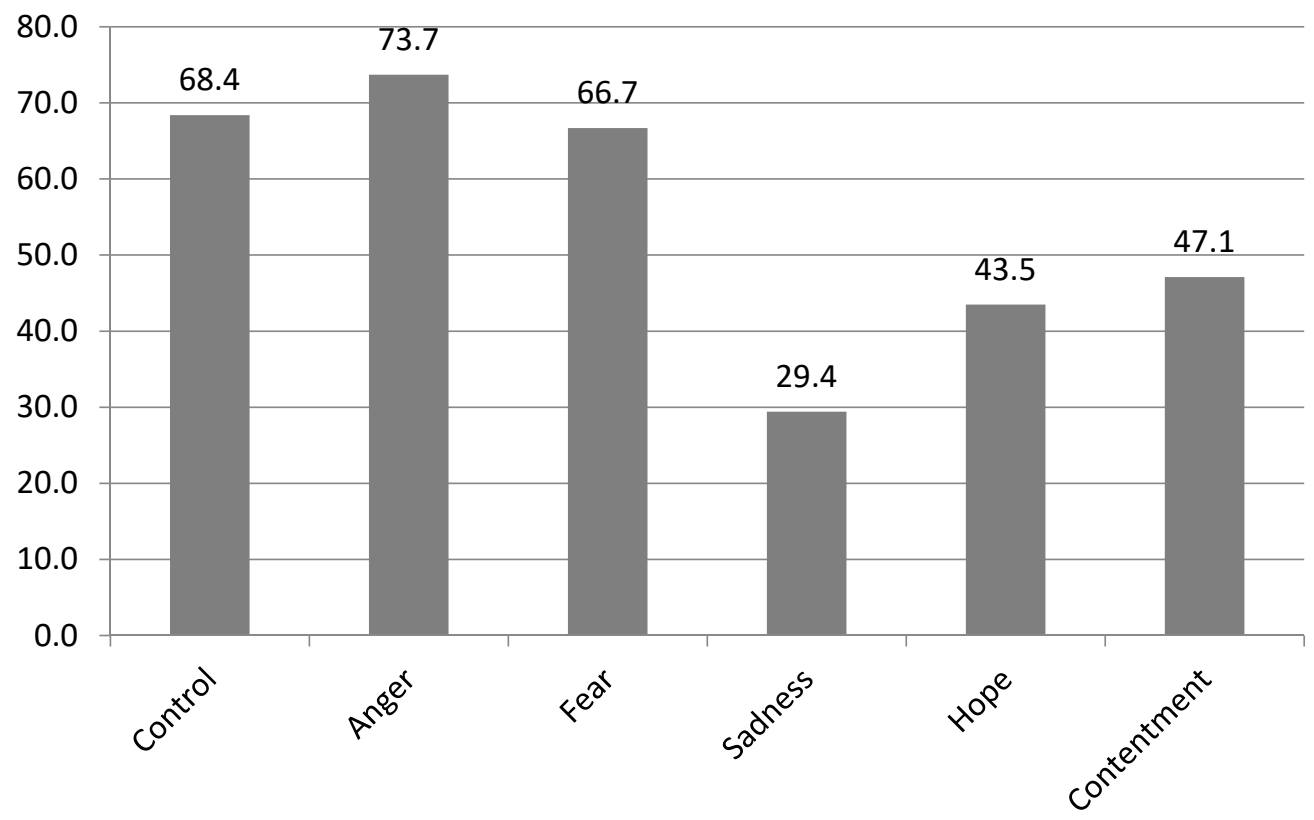

Figure 3. Percentage of Study 1 participants who requested more information, $\mathrm{N}=114$.

In Hypothesis 1, we predicted that sadness would result in less pro-environmental behavior than the control condition. This hypothesis was supported insofar as sadness resulted in significantly fewer requests than the control condition, $\chi^{2}(1, n=36)=4.01$, 
$p<0.05$. We found no support for Hypotheses 2 or 4 ; this is because neither fear nor anger elicited more information requests than the control condition-anger $\chi^{2}(1, n=38)=0.00$, $n$ s; fear $\chi^{2}(1, n=34)=0.00, n s$. We did find support for Hypotheses 3 and 5 , however, as the number of information requests from the sadness condition group was significantly lower than from the anger or fear condition groups-anger $\chi^{2}(1, n=36)=5.39, p<0.05$; fear $\chi^{2}(1, n=32)=4.44, p<0.05$.

We found no support for Hypothesis 6; this is because information requests from the anger condition group were essentially the same as from the fear condition group, $\chi^{2}(1, n=34)=0.00, n s$. We also failed to find support for Hypotheses 7 and 8 since we found no significant difference in requesting behavior between the control and the positive emotion condition groups-hope $\chi^{2}(1, n=42)=1.70, n s$; contentment $\chi^{2}(1, n=40)=0.92$, ns.

As we noted earlier, we found significant differences in information requests between the fear and sadness condition groups (Hypothesis 3), as well as between the anger and sadness condition groups (Hypothesis 5). However, we found no significant difference in the proportions of participants who requested information between the hope and the contentment condition groups, $\chi^{2}(1, n=40)=0.05, n s$. These results, therefore, provide support for the comparative Hypotheses $9 \mathrm{a}$ and $9 \mathrm{~b}$.

The results of Study 3 are also consistent with those from Studies 1 and 2 insofar as emotions significantly affected pro-environmental behavior. Furthermore, the results of Study 3 once again emphasize the importance of studying discrete emotions. The results show that participants who viewed the sad emotion report made fewer information requests than those in the neutral, anger, and fear condition groups. This finding demonstrates that, although anger, fear, and sadness share a negative valence, the behavioral outcomes of the conditions are significantly different. Thus, the findings of Study 3 lend empirical support to emotion scholars' assertions [32,69] that aggregating emotions based solely on valence can mask discrete emotion effects. Moreover, the results of Study 3 support the view that emotional arousal is less important for positive emotion as compared to negative emotion in motivating pro-environmental behavior.

\section{Discussion}

Our research makes three important contributions to the literature.

First, our use of a quasi-experimental design progresses the understanding of how the use of emotion in communicating a climate change message can significantly affect individual workplace pro-environmental behavior. Our findings advance the current research by showing how the emotional framing of climate change messaging has a causal effect on subsequent behavior, thus bolstering our current understanding in this regard [7,12].

Our second contribution is an extension of the knowledge regarding the role of discrete emotions and the need to differentiate between the effects of each emotion. Indeed, our research demonstrates that it is not enough to consider only emotional valance; it is also necessary to study the effect of discrete emotions [6,7]. We further found that discrete emotions with the same valence result in different outcomes. This is reflected in our findings that the negative emotions of anger, fear, and sadness did not affect subsequent behavior in the same way. We found that, compared to no emotion, sadness actually tends to suppress pro-environmental behavior, and that emotional arousal is important in differentiating the effects of negative emotion. This finding is in line with our predictions but differs from recent findings that sadness might have a positive impact on pro-environmental behavior [46]. We note that the manipulation in our study was focused on the lowest end of the arousal spectrum, which differed from previous work.

In all three studies, we found that the high arousal negative emotions of anger and fear led to more pro-environmental behavior than the low arousal negative emotion of sadness. However, the findings of all three studies revealed no significant differences between the emotions of anger and fear. This finding differs from Lerner and Keltner [43,49], who found that angry and fearful individuals made different decisions. This disparity is, however, consistent with affective events theory [38] in that the focus of our research 
was on affect-driven behaviors, whereas Lerner and Keltner's research was focused on judgment-driven behavior. Therefore, it is likely that the action orientation of the emotion is an important determinant of affect-driven behavior. Indeed, given that the focus of Lerner and Keltner's research was on cognitive judgments and choices, while the focus of our study was on observed behaviors, the differences between dependent variables could explain the disparity in findings. We argue, therefore, that this will likely be a fruitful area for future research.

In relation to positive emotion, our results consistently show no significant difference in measures of pro-environmental behavior between high and low arousal positive emotions. This finding is consistent with recent work that showed no significant effects of positively framed environmental messages on pro-environmental behavior [70]. Taken together, the results across both positive and negative conditions lend support to the negativity effect [59], whereby the effect of negative stimuli is greater than that of positive stimuli.

\section{Implications for Research and Practice}

Our findings have implications that may contribute to advancing knowledge in this area, as well as informing future interventions and communications designed to encourage pro-environmental behavior within and outside organizations. We note, however, that caution is needed when considering whether the use of intentional emotional framing in messaging is ethical. A recent review highlights the complexity in climate change messaging and urges caution (as we do) in assuming that the emotional framing of climate messages is a "silver bullet". There is simply not enough evidence yet to say with certainty how individuals are affected by different sorts of messages [54].

In our research, we found that high arousal negative emotions, such as anger or fear, led to more pro-environmental behavior than the low arousal negative emotion of sadness. We caution against focusing on eliciting anger and fear in order to encourage behavior change, however, especially given that it is possible that the elicitation of such negative emotions may inadvertently induce feelings of sadness and, subsequently, may cause inaction. In line with recent reviews $[6,7,54]$, we argue for a more nuanced understanding of the impact of emotionally-framed messaging in relation to climate change. In particular, there is a need for comprehensive message testing to ensure messaging does not result in feelings of sadness-and, subsequently, adverse behavior.

Our focus in this research was on the five emotions of sadness, fear, anger, contentment, and hope. It is likely that other emotions are relevant in understanding the effect of emotion on workplace pro-environmental behaviors and intentions [7]. While our work goes some way in advancing this field, more research is necessary to explore this burgeoning area further. For example, the use of hope in emotional communication is an area that is under increasing investigation $[3,7,12]$. Our results show that hope is not consistently more effective than other emotions in encouraging pro-environmental behavior. Thus, more research is necessary to unpack the role of hope and, indeed, other discrete emotions in climate change communication.

Researchers in the future should also consider longitudinal designs. While the findings from our studies demonstrate that emotion has a significant immediate impact on proenvironmental behavior immediately following the manipulations, it is not clear how long the effects of the manipulations last. A longitudinal design would enable researchers to test whether the effect of emotion endures over time [7] and to further explore the mechanisms that may influence longer-term cognitive responses such as information searching and self-directed thought or reappraisal and rumination [6].

We would also encourage future researchers to conduct more field-based research to improve external validity and to explore how emotion affects behavior in more field-based settings. While we attempted to maximize the external validity of our experimental results by conducting two controlled studies and a field study, our study is nonetheless limited by the contexts of participants as students and office workers. Thus, our results should be generalized with caution to other populations and manipulations in more natural settings. 
Finally, the investigation of the interactions of emotions with other variables would also help to advance the field [54]. In our research, we were most interested in examining the direct effects of emotions on pro-environmental behavior, so our focus was necessarily on the five discrete emotions we studied. We would, however, encourage future researchers to consider additional variables that may interact with the emotional framing of climate change messages. One recent study, for instance, suggested that self-efficacy may have a strong interaction with negative emotions to encourage more pro-environmental behavior [54]. Others have shown that there is an interaction between positive emotions and pro-environmental attitudes and norms $[9,29]$. Thus, the interactions between variables may be an important consideration for future work.

\section{Conclusions}

Our aim in this research was to examine, in three quasi-experimental studies, how climate change communication framed in different discrete emotions can affect subsequent pro-environmental behavior within a workplace context. We employed experimental manipulations that involved audio-visual stimuli designed to manipulate discrete emotions of sadness, fear, anger, contentment, and hope. The results from our studies demonstrate that emotion in communication has a direct causal effect on pro-environmental behavior, thus confirming the importance of emotion in understanding this behavior. Furthermore, the differences in the participants' pro-environmental behavior between the anger, fear and sadness condition groups underscores the importance of studying discrete emotions, rather than studying emotions aggregated into positive and negative valence.

Author Contributions: Both authors contributed to the study conception and design. Material preparation, data collection and analysis were performed by S.V.R. and supervised by N.M.A. Writing, reviewing and editing was led by S.V.R. and supervised by N.M.A. Funding was acquired by S.V.R. All authors have read and agreed to the published version of the manuscript.

Funding: This research was funded by Griffith University, the University of Queensland, and by the FP7 People: Marie Curie Actions (632035).

Institutional Review Board Statement: This research was conducted according to the guidelines of the Declaration of Helsinki, and approved by the Ethics Committee of Griffith University (protocol code MGT/21/09/HREC, 24-05-2010, 23-05-2010).

Informed Consent Statement: Informed consent was obtained from all subjects involved in the study.

Data Availability Statement: The data presented in this study are available upon request from the corresponding author. The data are not publicly available because this would contradict the ethical approvals granted for this study.

Acknowledgments: The authors are grateful to colleagues and peers who have given valuable feedback on earlier versions of this manuscript.

Conflicts of Interest: The authors declare no conflict of interest. The funders had no role in the design of the study; in the collection, analyses, or interpretation of data; in the writing of the manuscript, or in the decision to publish the results.

\section{Appendix A}

\section{Appendix A.1. Manipulation Check}

Our aim in designing the manipulations was to present emotional stimuli that would evoke the target emotions in participants. The videos were related to climate change because our theoretical propositions were that emotion arises in relation to climate change, and that this will have a direct effect on workplace pro-environmental behavior. In this way, the emotional stimuli comprised events that cause an affective reaction, and we aimed to examine the resulting affect-driven behavior. Hatfield, Cacioppo, and Rapson [71] suggested that individuals can "catch" emotions through a process of "emotional contagion." They concluded that people tend to mimic others and to synchronize their facial expressions, 
voice tone, posture, and movement. Furthermore, these authors argued that subjective emotional experiences are affected through the process of mimicry. Therefore, we ran a pilot study to test the effectiveness of our manipulations on participants' subjective emotional experiences following the viewing of the stimuli.

\section{Appendix A.1.1. Materials and Methods}

We recruited the pilot study participants from masters and senior undergraduate business courses at two universities located in the northeast of Australia (i.e., the same population was used for Studies 1 and 2). The sample included 60 respondents, $62 \%$ of whom were female, with an average age of 27 , ranging from 19 to 52 years. The participants were offered a small incentive of candy in return for their participation.

The participants viewed the six news reports (five treatment conditions and one control) and read a written transcript (control condition) of the news. After each manipulation, participants completed a survey that measured their emotional reactions to the videos or written news reports. We counterbalanced the order of presentation of the manipulations to avoid any effects from presentation order.

We measured discrete emotions to check the manipulations. Discrete emotion measures included sad, hopeless, fearful, angry, confident, content, and hopeful. We asked participants to rate the extent to which they experienced each emotion while watching the video or reading the news report. Participants rated each discrete emotion on a seven-point Likert-type scale ranging from "very slightly or not at all" to "extremely".

\section{Appendix A.1.2. Results}

Sadness: After watching the sadness manipulation, the participants reported experiencing significantly more sadness than when reading the neutral transcript (mean difference $=1.14, p<0.01$ ) or watching the neutral video (mean difference $=1.36, p<0.01$ ).

Fear: After watching the news report framed in fear, the participants reported experiencing significantly more fear than when reading the neutral transcript (mean difference $=$ $1.38, p<0.01$ ) or watching the neutral video (mean difference $=1.70, p<0.01$ ).

Anger: After watching the anger manipulation, the participants reported experiencing significantly more anger than when reading the neutral transcript (mean difference $=1.56$, $p<0.01$ ) or watching the neutral video (mean difference $=1.76, p<0.01$ ).

Contentment: Following the viewing of the contentment manipulation, the participants reported experiencing significantly more contentment than when reading the neutral transcript (mean difference $=0.99, p<0.01$ ) or watching the neutral video (mean difference $=0.84, p<0.01)$. After watching this condition, the participants also experienced more confidence than when reading the neutral transcript (mean difference $=1.64, p<0.01$ ) or watching the neutral video (mean difference $=1.72, p<0.01$ ).

Hope: Following the viewing of the hopeful manipulation video, the participants experienced significantly more hope than when reading the neutral transcript (mean difference $=0.90, p<0.01$ ) or watching the neutral video (mean difference $=1.24, p<0.01$ ). The participants also experienced significantly more joy after watching the hopeful video than when reading the neutral transcript (mean difference $=1.51, p<0.01$ ) or watching the neutral video (mean difference $=1.52, p<0.01$ ).

In summary, these results suggest that we succeeded in arousing each discrete emotion (as we intended via the manipulations).

\section{References}

1. IPCC. Global Warming of $1.5^{\circ} \mathrm{C}$. An IPCC Special Report on the Impacts of Global Warming of $1.5^{\circ} \mathrm{C}$ above Pre-industrial Levels and Related Global Greenhouse Gas Emission Pathways, in the Context of Strengthening the Global Response to the Threat of Climate Change, Sustainable Development, and Efforts to Eradicate Poverty; IPCC: Geneva, Switzerland, 2018.

2. Reser, J.P.; Swim, J.K. Adapting to and coping with the threat and impacts of climate change. Am. Psychol. 2011, 66, 277-289. [CrossRef]

3. Ojala, M. Hope and climate change: The importance of hope for environmental engagement among young people. Environ. Educ. Res. 2012, 18, 625-642. [CrossRef] 
4. Wang, S.; Leviston, Z.; Hurlstone, M.; Lawrence, C.; Walker, I. Emotions predict policy support: Why it matters how people feel about climate change. Glob. Environ. Chang. 2018, 50, 25-40. [CrossRef]

5. Stern, P.C. Psychology: Fear and hope in climate messages. Nat. Clim. Chang. 2012, 2, 572-573. [CrossRef]

6. Chapman, D.; Lickel, B.; Markowitz, E.M. Reassessing emotion in climate change communication. Nat. Clim. Chang. 2017, 7, 850-852. [CrossRef]

7. Brosch, T. Affect and emotions as drivers of climate change perception and action: A review. Curr. Opin. Behav. Sci. 2021, 42, 15-21. [CrossRef]

8. Van der Linden, S. Intrinsic motivation and pro-environmental behaviour. Nat. Clim. Chang. 2015, 5, 612-613. [CrossRef]

9. Bissing-Olson, M.J.; Iyer, A.; Fielding, K.; Zacher, H. Relationships between daily affect and pro-environmental behavior at work: The moderating role of pro-environmental attitude. J. Organ. Behav. 2012, 34, 156-175. [CrossRef]

10. Markowitz, E.; Shariff, A. Climate change and moral judgement. Nat. Clim. Chang. 2012, 2, 243-247. [CrossRef]

11. O'Neill, S.; Nicholson-Cole, S. "Fear Won't Do It" Promoting positive engagement with climate change through visual and iconic representations. Sci. Commun. 2009, 30, 355-379. [CrossRef]

12. Hornsey, M.; Fielding, K. A cautionary note about messages of hope: Focusing on progress in reducing carbon emissions weakens mitigation motivation. Glob. Environ. Chang. 2016, 39, 26-34. [CrossRef]

13. Wright, C.; Nyberg, D. An Inconvenient Truth: How Organizations Translate Climate Change into Business as Usual. Acad. Manag. J. 2017, 60, 1633-1661. [CrossRef]

14. Unsworth, K.L.; Davis, M.C.; Russell, S.V.; Bretter, C. Employee green behaviour: How organizations can help the environment. Curr. Opin. Psychol. 2020, 42, 1-6. [CrossRef] [PubMed]

15. Carmeli, A.; Brammer, S.; Gomes, E.; Tarba, S.Y. An organizational ethic of care and employee involvement in sustainability-related behaviors: A social identity perspective. J. Organ. Behav. 2017, 38, 1380-1395. [CrossRef]

16. Molina-Azorin, J.; López-Gamero, M.; Tarí, J.; Pereira-Moliner, J.; Pertusa-Ortega, E. Environmental Management, Human Resource Management and Green Human Resource Management: A Literature Review. Adm. Sci. 2021, 11, 48. [CrossRef]

17. Robertson, J.L.; Barling, J. Greening organizations through leaders' influence on employees' pro-environmental behaviors. J. Organ. Behav. 2012, 34, 176-194. [CrossRef]

18. Ones, D.S.; Dilchert, S. Employee green behaviors. In Managing Human Resources for Environmental Sustainability; Jackson, S.E., Ones, D.S., Dilchert, S., Eds.; Jossey-Bass: San Francisco, CA, USA, 2012; pp. 85-116.

19. Norton, T.A.; Parker, S.L.; Davis, M.C.; Russell, S.V.; Ashkanasy, N.M. A virtuous cycle: How green companies grow green employees (and vice versa). In Research Handbook on Employee Pro-Environmental Behaviour; Wells, V., Gregory-Smith, D., Manika, D., Eds.; Edward Elgar Publishing: Cheltenham, UK, 2018; pp. 210-228.

20. Norton, T.A.; Parker, S.; Zacher, H.; Ashkanasy, N.M. Employee Green Behavior: A theoretical framework, multilevel review, and future research agenda. Organ. Environ. 2015, 28, 103-125. [CrossRef]

21. Young, W.; Davis, M.; McNeill, I.; Malhotra, B.; Russell, S.; Unsworth, K.L.; Clegg, C.W. Changing Behaviour: Successful Environmental Programmes in the Workplace. Bus. Strat. Environ. 2013, 24, 689-703. [CrossRef]

22. Aguinis, H.; Glavas, A. What We Know and Don't Know About Corporate Social Responsibility: A review and research agenda. J. Manag. 2012, 38, 932-968. [CrossRef]

23. Jones, D.A.; Newman, A.; Shao, R.; Cooke, F.L. Advances in Employee-Focused Micro-Level Research on Corporate Social Responsibility: Situating New Contributions Within the Current State of the Literature. J. Bus. Ethics 2018, 157, 293-302. [CrossRef]

24. Ajzen, I. The theory of planned behavior. Organ. Behav. Hum. Decis. Process. 1991, 50, 179-211. [CrossRef]

25. Stern, P.C. New Environmental Theories: Toward a Coherent Theory of Environmentally Significant Behavior. J. Soc. Issues 2000, 56, 407-424. [CrossRef]

26. Davis, M.C.; Unsworth, K.L.; Russell, S.V.; Galvan, J.J. Can green behaviors really be increased for all employees? Trade-offs for "deep greens" in a goal-oriented green human resource management intervention. Bus. Strat. Environ. 2019, 29, 335-346. [CrossRef]

27. Tian, Q.; Robertson, J.L. How and When Does Perceived CSR Affect Employees' Engagement in Voluntary Pro-environmental Behavior? J. Bus. Ethic 2017, 155, 399-412. [CrossRef]

28. Russell, S.V.; Giæver, F.; Onkila, T. Employee agency in the context of organisational sustainability. In Research Handbook of Sustainability Agency; Teerikangas, S., Onkila, T., Koistinen, K., Mäkelä, M., Eds.; Edward Elgar Publishing: Cheltenham, UK, 2021.

29. Bissing-Olson, M.J.; Fielding, K.; Iyer, A. Experiences of pride, not guilt, predict pro-environmental behavior when proenvironmental descriptive norms are more positive. J. Environ. Psychol. 2016, 45, 145-153. [CrossRef]

30. Wright, C.; Nyberg, D. Working with passion: Emotionology, corporate environmentalism and climate change. Hum. Relat. 2012, 65, 1561-1587. [CrossRef]

31. Barrett, L.F.; Russell, J.A. Independence and bipolarity in the structure of current affect. J. Pers. Soc. Psychol. 1998, 74, 967-984. [CrossRef]

32. Seo, M.-G.; Barrett, L.F.; Jin, S. The structure of affect: History, theory, and implications for emotion research in organizations. In Research Companion to Emotions in Organizations; Ashkanasy, N.M., Cooper, C.L., Eds.; New Horizons in Management Series; Edwin Elgar Publishing: Cheltenham, UK, 2008; pp. 17-44.

33. Clore, G.L.; Schiller, A.J.; Shaked, A. Affect and cognition: Three principles. Curr. Opin. Behav. Sci. 2017, 19, 78-82. [CrossRef] 
34. Scherer, K.R. Appraisal theory. In Handbook of Cognition and Emotion; Dalgleish, T., Power, M.J., Eds.; John Wiley \& Sons: Chichester, UK, 1999; pp. 637-663.

35. Lazarus, R.S. Emotion and Adaptation; Oxford University Press: New York, NY, USA, 1991.

36. Ashkanasy, N.M.; Dorris, A. Emotions in the Workplace. Annu. Rev. Organ. Psychol. Organ. Behav. 2017, 4, 67-90. [CrossRef]

37. Wright, C.; Nyberg, D.; Grant, D. "Hippies on the third floor": Climate Change, Narrative Identity and the Micro-Politics of Corporate Environmentalism. Organ. Stud. 2012, 33, 1451-1475. [CrossRef]

38. Weiss, H.M.; Cropanzano, R. Affective Events Theory: A theoretical discussion of the structure, causes and consequences of affective experiences at work. In Research in Organizational Behavior: An Annual Series of Analytical Essays and Critical Reviews; Staw, B.M., Cummings, L.L., Eds.; Elsevier Science/JAI Press: San Jose CA, USA, 1996; Volume 18, pp. 1-74.

39. Weiss, H.M.; Beal, D.J. Reflections on Affective Events Theory. In Research on Emotion in Organizations; Emerald Group Publishing Limited: Bingley, UK, 2005; Volume 1, pp. 1-21.

40. Blomfield, J.M.; Troth, A.C.; Jordan, P.J. Emotional Thresholds and Change Agent Success in Corporate Sustainability. Emot. Organ. Gov. 2016, 12, 191-216. [CrossRef]

41. Smith, N.; Leiserowitz, A. The Role of Emotion in Global Warming Policy Support and Opposition. Risk Anal. 2013, 34, 937-948. [CrossRef]

42. Baek, T.H.; Yoon, S. Guilt and Shame: Environmental Message Framing Effects. J. Advert. 2017, 46, 440-453. [CrossRef]

43. Lerner, D.K.J.S.; Keltner, D. Beyond valence: Toward a model of emotion-specific influences on judgement and choice. Cogn. Emot. 2000, 14, 473-493. [CrossRef]

44. Vries, G. Public Communication as a Tool to Implement Environmental Policies. Soc. Issues Policy Rev. 2019, 14, $244-272$. [CrossRef]

45. Russell, J.A. A circumplex model of affect. J. Pers. Soc. Psychol. 1980, 39, 1161-1178. [CrossRef]

46. Schwartz, D.; Loewenstein, G. The Chill of the Moment: Emotions and Proenvironmental Behavior. J. Public Policy Mark. 2017, 36, 255-268. [CrossRef]

47. Higgins, E.T. Promotion and prevention experiences: Relating emotions to nonemotional motivational states. In Handbook of Affect and Social Cognition; Forgas, J.P., Ed.; Erlbaum: Mahwah, NJ, USA, 2001; pp. 186-211.

48. So, J.; Kuang, K.; Cho, H. Reexamining Fear Appeal Models from Cognitive Appraisal Theory and Functional Emotion Theory Perspectives. Commun. Monogr. 2015, 83, 120-144. [CrossRef]

49. Lerner, J.S.; Keltner, D. Fear, anger, and risk. J. Pers. Soc. Psychol. 2001, 81, 146-159. [CrossRef]

50. Miceli, M.; Castelfranchi, C. Anger and Its Cousins. Emot. Rev. 2017, 11, 13-26. [CrossRef]

51. Frijda, N.H.; Kuipers, P.; ter Schure, E. Relations among emotion, appraisal, and emotional action readiness. J. Pers. Soc. Psychol. 1989, 57, 212-228. [CrossRef]

52. Lerner, J.S.; Tiedens, L.Z. Portrait of the angry decision maker: How appraisal tendencies shape anger's influence on cognition. J. Behav. Decis. Mak. 2006, 19, 115-137. [CrossRef]

53. Isen, A.M. Positive affect. In Handbook of Cognition and Emotion; Dalgleish, T., Power, M.J., Eds.; John Wiley \& Sons: Chichester, UK, 1999; pp. 521-540.

54. Hornsey, M.J.; Fielding, K.S. Understanding (and Reducing) Inaction on Climate Change. Soc. Issues Policy Rev. $2019,14,3-35$. [CrossRef]

55. Feldman, L.A. Valence focus and arousal focus: Individual differences in the structure of affective experience. J. Pers. Soc. Psychol. 1995, 69, 153-166. [CrossRef]

56. Lazarus, R.S. Hope: An emotion and a vital coping resource against despair. Soc. Res. 1999, 66, 653-678.

57. Feldman, L.; Hart, P.S. Using Political Efficacy Messages to Increase Climate Activism. Sci. Commun. 2015, 38, 99-127. [CrossRef]

58. Marlon, J.R.; Bloodhart, B.; Ballew, M.T.; Rolfe-Redding, J.; Roser-Renouf, C.; Leiserowitz, A.; Maibach, E. How Hope and Doubt Affect Climate Change Mobilization. Front. Commun. 2019, 4. [CrossRef]

59. Lewicka, M.; Czapinski, J.; Peeters, G. Positive-negative asymmetry or 'When the heart needs a reason'. Eur. J. Soc. Psychol. 1992, 22, 425-434. [CrossRef]

60. Erez, A.; Isen, A.M. The influence of positive affect on the components of expectancy motivation. J. Appl. Psychol. 2002, 87, 1055-1067. [CrossRef]

61. Soroka, S.; Fournier, P.; Nir, L. Cross-national evidence of a negativity bias in psychophysiological reactions to news. Proc. Natl. Acad. Sci. USA 2019, 116, 18888-18892. [CrossRef]

62. Ekman, P.; Friesen, W.V. Facial Action Coding System: Investigator's Guide; Consulting Psychologists Press: Palo Alto, CA, USA, 1978.

63. Lang, P.J.; Bradley, M.M.; Cuthbert, B.N. International Affective Picture System (IAPS): Affective Ratings of Pictures and Instruction Manual; Technical Report A-6; University of Florida: Gainesville, FL, USA, 2005.

64. Reynolds, W.M. Development of reliable and valid short forms of the Marlowe-Crowne Scale of social desirability. J. Clin. Psychol. 1982, 38, 119-125. [CrossRef]

65. Koehler, M.; Yadav, A.; Phillips, M.; Cavazos-Kottke, S. What is video good for? Examining how media and story genre interact. J. Educ. Multimed. Hypermedia 2005, 14, 249-272.

66. Cook, T.D.; Campbell, D.T. Quasi-Experimentation: Design and Analysis Issues for Field Settings; Rand McNally College Publishing Company: Chicago, IL, USA, 1979. 
67. Tabachnick, B.G.; Fidell, L.S. Using Multivariate Statistics, 4th ed.; Allyn and Bacon: Boston, MA, USA, 2001.

68. Damasio, A.R. Descartes' Error: Emotion, Reason, and the Human Brain; Putnam: New York, NY, USA, 1994.

69. Briner, R.B.; Kiefer, T. Psychological research into the experience of emotion at work: Definitely older, but are we any wiser? In The Effect of Affect in Organizational Settings; Ashkanasy, N.M., Härtel, C.E.J., Zerbe, W.J., Eds.; Elsevier JAI: Amsterdam, The Netherlands, 2005; Volume 1, pp. 281-307.

70. Lange, F.; Dewitte, S. Positive affect and pro-environmental behavior: A preregistered experiment. J. Econ. Psychol. 2020, 80, 102291. [CrossRef]

71. Hatfield, E.; Cacioppo, J.T.; Rapson, R.L. Emotional Contagion; Cambridge University Press: Cambridge, UK, 1994. 